\title{
The ISN COMGAN Continuing Medical Education program
}

\author{
Norbert Lameire
}

The leadership of the International Society of Nephrology's (ISN's) Commission for the Global Advancement of Nephrology (COMGAN) oversees the activities of five working regional subcommittees representing Africa, Asia, Central and South America, Eastern and Central Europe, and the Commonwealth of Independent States (the former Soviet Union) and the Middle East. COMGAN's goals, which have remained remarkably constant over the years, are to assist in strengthening patient care, research, and education; to provide regional postgraduate courses; to solicit and establish institutional partnerships; to create a leadership council of representatives from developing countries; and to reinforce the programs of national societies. Courses organized by COMGAN's Continuing Medical Education (CME) program quickly became the principal mechanism for achieving these goals.

CME courses are organized by the program chair, together with the event organizers and regional subcommittees. COMGAN provides financial assistance, advice on organizing a scientific course that will meet the needs of the local nephrological community, and help in selecting appropriate speakers. The program sponsors the attendance of these expert nephrologists, who provide up-to-date information on basic and clinical nephrology, dialysis, transplantation, and epidemiology of kidney diseases, both in adults and in children. Approximately 50 courses per year have been organized. About 11,000 physicians per year are educated during these courses.

Over the past year, COMGAN has been restructured and is now based on a 'cabinet' model. One of the aims of the restructure was to better integrate COMGAN's different activities (e.g. CME, Sister Renal Centers, and fellowship programs). As a consequence,

\section{Approximately \\ 50 courses per \\ year have been \\ organized. \\ About 11,000 \\ physicians \\ per year are \\ educated \\ during these \\ courses.}

N Lameire is Chair of the COMGAN CME

program and Emeritus Professor of Medicine, University Hospital, Ghent, Belgium.

\section{Competing interests}

The author declared he has no competing interests.

www.nature.com/clinicalpractice doi:10.1038/ncpneph0425 priority for CME courses is given to locations with an active Sister Renal Center and, whenever possible, former or current ISN fellows are invited to participate. At least one lecture per course focuses on prevention and screening of chronic kidney disease in the area of the world hosting the course.

It was also felt that the need to provide updated nephrological information is greater in certain parts of the globe. As such, great effort is being made to promote CME activities in sub-Saharan Africa. Fortunately, in the past 10 years, many Eastern European countries have made enormous progress, and now have improved access to literature and congresses. Active cooperation between the CME programs of COMGAN and the European Renal Association-European Dialysis and Transplant Association has also been established. The ISN can, therefore, gradually decrease its financial support for CME activities in this part of the world, providing the means to expand its support for CME in areas such as Africa (see Supplementary Figure 1 online for geographical distribution of 2006 CME activities).

Understandably, the content of previous CME courses was primarily a function of the availability of guest speakers. Now, regional subcommittees of COMGAN are becoming ever more involved in organizing CME courses. We hope that future courses will thereby be increasingly focused on local needs.

For more information on COMGAN's CME program, please visit the ISN Nephrology Gateway (www.isn-online.org), email isabel.vandorpe@ ugent.be, or contact An Devriese at ISN Global Headquarters (an@associationhq.com).

Supplementary information is available on the Nature Clinical Practice Nephrology website. 